\title{
Subsidence at Kiska Volcano, Western Aleutians, detected by satellite radar interferometry
}

\author{
Zhong Lu, ${ }^{1}$ Tim Masterlark, ${ }^{1}$ John Power, ${ }^{2}$ Daniel Dzurisin, ${ }^{3}$ and Charles Wicks ${ }^{4}$ \\ Received 19 February 2002; revised 21 May 2002; accepted 22 May 2002; published 17 September 2002.
}

[1] Sequential interferometric synthetic aperture radar images of Kiska, the westernmost historically active volcano in the Aleutian arc, show that a circular area about $3 \mathrm{~km}$ in diameter centered near the summit subsided by as much as $10 \mathrm{~cm}$ from 1995 to 2001, mostly during 1999 and 2000. An elastic Mogi-type deformation model suggests that the source is within $1 \mathrm{~km}$ of the surface. Based on the shallow source depth, the copious amounts of steam during recent eruptions, and recent field reports of vigorous steaming and persistent ground shaking near the summit area, we attribute the subsidence to decreased pore-fluid pressure within a shallow hydrothermal system beneath the summit area. INDEX TERMS: 8419 Volcanology: Eruption monitoring (7280); 8499 Volcanology: General or miscellaneous; 6924 Radio Science: Interferometry. Citation: Lu, Z., T. Masterlark, J. Power, D. Dzurisin, and C. Wicks, Subsidence at Kiska Volcano, Western Aleutians, detected by satellite radar interferometry, Geophys. Res. Lett., 29(18), 1855, doi:10.1029/ 2002GL014948, 2002.

\section{Introduction}

[2] Kiska, the westernmost historically active volcano in the Aleutian arc, Alaska, is about $8 \mathrm{~km}$ in diameter at its base, $1220 \mathrm{~m}$ high, and occupies the northern end of Kiska island (Figure 1). The summit crater, about $0.4 \mathrm{~km}$ in diameter and breached on the north, reveals interbedded lava flows and pyroclastic deposits that are largely devoid of vegetation at higher elevations. Heavy grass and associated vegetation dominate near the coast, and perennial snow patches cover the upper slopes. Eruptions were reported in 1962, 1964, 1969, 1987, and 1990. They have been characterized by relatively small plumes of ash, significant amounts of steam, and occasional lava flows; each lasted for several hours to a few days [Miller et al., 1998]. Owing to the remote setting and lack of instrumentation, remotely sensed observations, such as synthetic aperture radar (SAR) imagery, play a key role for studying Kiska volcano.

[3] Interferometric SAR (InSAR) is a remote sensing technique that has been used successfully in recent years to study volcanoes worldwide [e.g., Massonnet and Feigl, 1998]. Interferograms are formed by combining SAR images taken at different times with a digital elevation model (DEM) of the terrain. The resulting image contains information

\footnotetext{
${ }^{1}$ U.S. Geological Survey (USGS), EROS Data Center, Raytheon ITSS, Sioux Falls, SD, USA.

${ }^{2}$ USGS, Alaska Volcano Observatory, Anchorage, AK, USA.

${ }^{3}$ USGS, Cascades Volcano Observatory, Vancouver, WA, USA

${ }^{4}$ USGS, Menlo Park, CA, USA.
}

about any surface displacements that might have occurred between the acquisition times of the SAR images. Deformation is mapped in the interferogram as the distribution of three-dimensional surface displacements projected onto a satellite line-of-sight (LOS) vector, with accuracies of 1-2 $\mathrm{cm}$ and horizontal resolution of 20-30 m. InSAR has been used recently to study both eruptive and non-eruptive activity at several volcanoes in the Aleutian volcanic arc [e.g., Lu et al., 2002]. In this paper, we use C-band (wavelength $=5.66 \mathrm{~cm})$ SAR images collected by ERS-1 and ERS2 satellites (descending passes) during arctic summers (June to October) from 1995 to 2001 to measure subsidence near the summit of Kiska, which we attribute to decreased porefluid pressure within the shallow hydrothermal system.

\section{InSAR Deformation}

[4] The number of ERS-1 and ERS-2 SAR images of Kiska volcano is limited by scant requests for data acquisitions over the area. We used the available SAR images from the summers of 1995 and 1998-2001 to generate seven interferograms (Figure 2), using a two-pass InSAR technique combined with a U.S. Geological Survey (USGS) DEM [e.g., Massonnet and Feigl, 1998]. The DEM has a specified $90 \mathrm{~m}$ horizontal resolution and $30 \mathrm{~m}$ vertical accuracy at the $90 \%$ confidence level. The Kiska DEM was resampled into 20-m pixel spacing to match the SAR image resolution for removal of topographic contributions in the original interferograms. We first generated a 35-day interferogram with altitude of ambiguity, $h_{a}$, equal to $58 \mathrm{~m}$. The interferogram spans the interval from August 21 to September 25, 2000 (Figure 2k), and is used to check the overall accuracy of the DEM. No apparent range change larger than $2-3 \mathrm{~cm}$ is observed in this interferogram. Any smaller signals are not likely due to deformation, as they appear fairly random; they are more likely due to DEM errors or atmospheric disturbances. Other interferograms used in this study have $h_{a}$ ranging from $1879 \mathrm{~m}$ to $160 \mathrm{~m}$. They are therefore much less sensitive to DEM errors than the 35-day interferogram. We conclude that the effect of any errors in the DEM on the interferograms used for our deformation analysis is negligible (Figures 2).

[5] An interferogram for the time period from October 1, 1995 , to September 25, $2000\left(h_{a}=539 \mathrm{~m}\right)$ is shown in Figure 2a. Each fringe, or full color cycle, represents $2.83 \mathrm{~cm}$ (onehalf of the radar wavelength) of range change, which we interpret as mainly surface displacement, along the satellite LOS. The unit look vector, defined by [east, north, up] is $[0.402,-0.093,0.910]$. Therefore, the interferogram is much more sensitive to the vertical component of the displacement vector than to the horizontal component. About two and a half arcuate fringes near the summit area 


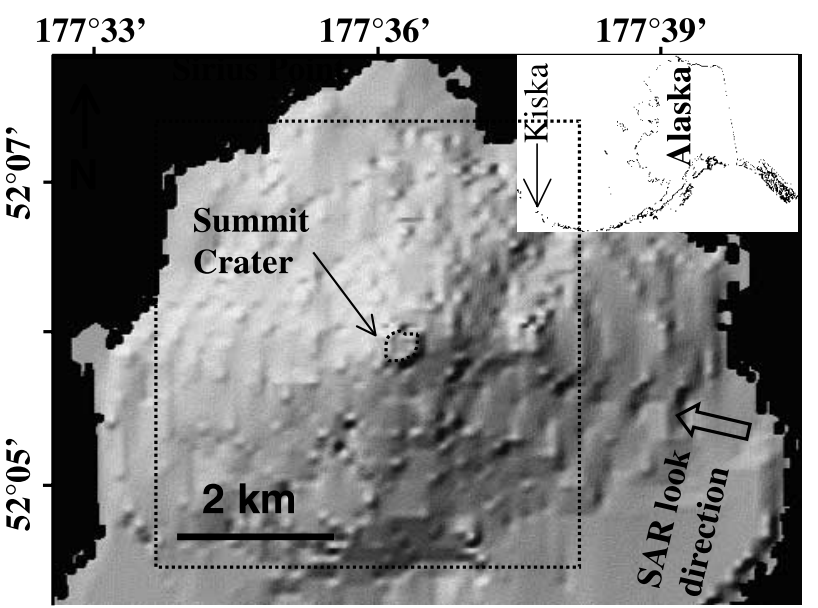

Figure 1. Shaded-relief image of Kiska Volcano near the western tip of the Aleutian volcanic arc. The dashed white rectangle represents the coverage of interferograms shown in Figure 2.

are visible in Figure 2a, suggesting displacement of the upper part of the volcano by more than $7 \mathrm{~cm}$ between 1995 and 2000. The transition of colors, from red to yellow to blue, represents an increase of LOS distance between the satellite and the ground surface, which corresponds to subsidence of the surface. The largest displacements might be expected near the center of the summit crater, but this region does not maintain coherence due to persistent snow cover and therefore the interferograms contain no direct information about surface displacements in this area.

[6] An interferogram for the time period from October 10, 1998, to October 14, $2000\left(h_{a}=441 \mathrm{~m}\right)$ is shown in Figure $2 \mathrm{~b}$. The unit look vector for this image, $[0.344,-0.080$, 0.935 ], is slightly different from that for Figure 2a, although both images suggest more than $7 \mathrm{~cm}$ of displacement projected onto the LOS vectors. The images in Figures 2a and $2 \mathrm{~b}$ do not share a common acquisition date and were taken with slightly different viewing geometries. Because the topographic relief over the subsidence area is less than $600 \mathrm{~m}$, and topography-correlated fringes are not present in the 35-day interferogram (Figure 2k), it is unlikely that the subsidence of more than $7 \mathrm{~cm}$ in Figures $2 \mathrm{a}$ and $2 \mathrm{~b}$ is an artifact caused by atmospheric anomalies [e.g., Massonnet and Feigl, 1998; Delacourt et al., 1998]. Likewise, the fringes cannot have been caused by DEM errors, because the altitudes of ambiguity for the two interferograms (539 m and $441 \mathrm{~m}$, respectively) are much larger than that for the 35day interferogram (Figure 2k), which exhibits negligible DEM errors. Therefore, we conclude that the fringe patterns in Figures $2 \mathrm{a}$ and $2 \mathrm{~b}$ were caused by more than $7 \mathrm{~cm}$ of subsidence centered near the summit area, and most of the deformation occurred sometime during 1998-2000.

[7] An interferogram for the period from August 2, 1999 to August 21, $2000\left(h_{a}=486 \mathrm{~m}\right)$ is shown in Figure 2c. The unit look vector is the same as that for Figure 2a. The fringe pattern is similar to those in Figures $2 a$ and $2 b$ and the area of interferometric coherence in the summit area is greater, so the subsidence pattern is more completely revealed.

[8] A fourth interferogram, this one for the time interval from June 28, 1999 to September 25, $2000\left(h_{a}=1879 \mathrm{~m}\right)$ is shown in Figure 2d. The unit look vector is the same as those for Figures 2a and 2c. Because one of the images was acquired in late June, when we presume a snow pack was present on the upper slopes of the volcano, this interferogram suffers from severe loss of coherence over the summit crater area. Less than one fringe, corresponding to the outermost portion of the fringes shown in Figures $2 \mathrm{a}-2 \mathrm{c}$, is visible.

[9] Two other interferograms suggest continued subsidence of the volcano during 2000-2001: one from October 4, 2000, to July 21, $2001\left(h_{a}=172 \mathrm{~m}\right.$, Figure $\left.2 \mathrm{i}\right)$, and the other from October 4, 2000, to August 25, $2001\left(h_{a}=122 \mathrm{~m}\right.$, Figure 2j). The amount of subsidence during 2000-2001 $(0.9-2.2 \mathrm{~cm})$ is much less than during 1999-2000 (Figures $2 \mathrm{c}$ and $2 \mathrm{~d}$ ), but the subsidence pattern is otherwise similar.

\section{Deformation Modeling}

[10] On the basis of the symmetric convergence patterns of surface displacement in Figure 2, we consider two explanations for the observed subsidence: 1) a pressure decrease within a spherical magma chamber [e.g., Mogi, 1958], and 2) a reduction of pore-fluid pressure within a spherical volume [e.g., Wang, 2000]. The displacement vector, $u$, for both mechanisms can be estimated with a tension-sphere source within a homogenous elastic halfspace. We specify a Cartesian coordinate system with east, north, and up axes having an origin collocated with the upper-left (northwest) corner of Figure 1. The displacement at the free-surface $\left(x_{3}=0\right)$ takes the form,

$$
u_{i}\left(x_{1}-x_{1}^{\prime}, x_{2}-x_{2}^{\prime}, 0\right)=C \frac{x_{i}-x_{i}^{\prime}}{|R|^{3}}
$$

for a source located at $x_{i}^{\prime}$, where $-x_{3}^{\prime}$ is the depth of the source, $C$ is a combination of material properties and source strength, and $R$ is the distance between the source and the displacement location. For the case of a depressurizing magma chamber,

$$
C=\Delta P(1-v) \frac{r^{3}}{G}=\Delta V \frac{(1-v)(1+v)}{2 \pi(1-2 v)}
$$

where $\Delta P$ is the change in pressure along the surface of the spherical magma chamber, $v$ is Poisson's ratio, $r$ is the radius of the chamber, and $G$ is the shear modulus. Alternatively, the source can be expressed as a change in volume of the magma chamber $(\Delta V)$. For the case of an expanding or contracting magma chamber, the predicted $\Delta V$ is dependent upon the choice of $v$, as shown in equation (2).

[11] For a poroelastic source, the displacement is proportional to the change in pore-fluid pressure $\left(\Delta P_{f}\right)$ within a spherical volume $(V)$ of a poroelastic material,

$$
C=\Delta P_{f} V \frac{c_{m}(1-v)}{\pi}
$$

where $c_{m}$ is Geertsma's uniaxial poroelastic expansion coefficient [Wang, 2000]. For a poroelastic source, estimations of $\Delta P_{f} V$ can range over an order of magnitude depending upon the choices made for $v$ and $c_{m}$ [Wang, 2000]. The ambiguity of $C$ does not allow us to discriminate between magmatic or poroelastic sources based on observed deformation alone. 


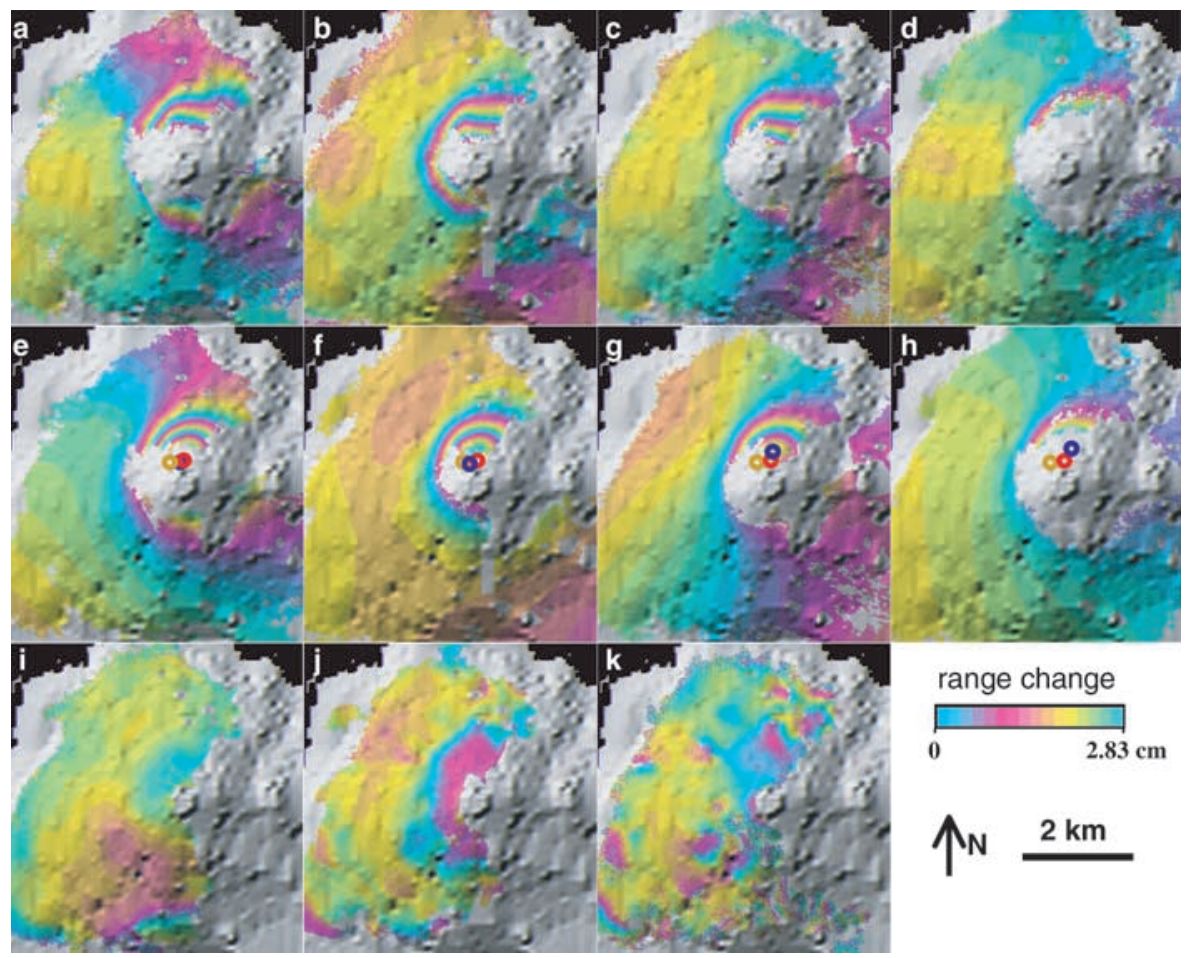

Figure 2. Observed and modeled interferograms that show time-varying subsidence near the summit of Kiska volcano from 1995 to 2001. The areal extent of the interferograms is shown in Figure 1. The interferograms cover the following time periods: (a) observed and (e) modeled interferograms spanning Oct. 1, 1995 to Sept. $25,2000\left(h_{a}=539 \mathrm{~m}\right)$; (b) observed and (f) modeled interferograms spanning Oct. 10, 1998 to Oct. 14, 2000 ( $\left.h_{a}=441 \mathrm{~m}\right)$; (c) observed and (g) modeled interferograms spanning Aug. 2, 1999 to Aug. 21, 2000 ( $\left.h_{a}=486 \mathrm{~m}\right)$; (d) observed and (h) modeled interferograms spanning Jun. 28, 1999 to Sept. 25, 2000 ( $\left.h_{a}=1879 \mathrm{~m}\right)$; (i) observed interferogram spanning Oct. 4, 2000 to Jul. 21, $2001\left(h_{a}=172 \mathrm{~m}\right)$; (j) observed interferogram spanning Oct. 4, 2000 to Aug. 25, $2001\left(h_{a}=122 \mathrm{~m}\right)$; and $(\mathrm{k})$ observed interferogram spanning Aug. 21, 2000 to Sept. 25, $2000\left(h_{a}=58 \mathrm{~m}\right)$, which was used to verify overall accuracy of the DEM. The orange circle represents a vigorous steam vent reported by Jones et al. [2001]. Blue circles represent surface projections of locations for source models that best fit individual interferograms (Table 1). The red circle is the fixed source location based on the average of locations of individually best-fit models. The modeled interferograms are calculated based on the fixed source location. A full cycle of colors (i.e., one interferometric fringe) represents $2.83 \mathrm{~cm}$ of surface displacement along the LOS. Areas without interferometric coherence are uncolored. Interferometric phase images are shown superimposed on the shaded-relief image.

[12] For each of the InSAR images having significant deformation signals (Figures $2 \mathrm{a}$ and $2 \mathrm{j}$ ), we determine the optimal set of parameters for the location of the source and its strength. We introduce in our model linear terms to account for possible errors in determination of satellite positions, which might not be completely compensated during interferogram processing [Massonnet and Feigl, 1998]. Best-fitting model parameters and uncertainties are determined via a non-linear least-squares inversion approach [Press et al., 1992]. To account for topographic effects, we adopt a simple method proposed by Williams and Wadge [1998], in which the elevation of the reference surface varies according to the elevation of each computation point in the model. Because the estimated source locations determined for each of the five InSAR images do not vary significantly (Table 1), and because the depthstrength ambiguity is inherent in inversion of vertical displacements [Dieterich and Decker, 1975] that dominate the InSAR line of sight vector, we assume a constant source location (the average of $x_{i}^{\prime}$ ). For this configuration, equation
(1) is linearized and we re-estimate the source strength using a linear least-squares inversion method. For the constant source location configuration, estimated parameters are summarized in Table 1 and corresponding model predictions are shown in Figures $2 \mathrm{e}-2 \mathrm{~h}$.

Table 1. Optimal Model Parameters for Interferograms Showing Significant Deformation Signals

\begin{tabular}{cccccc}
\hline Image Dates & 951001 & 981010 & 990802 & 990628 & 001004 \\
& 000925 & 001014 & 000821 & 000925 & 010825 \\
\hline$x_{1}^{\prime}(\mathrm{m})$ & 7424 & 7381 & 7471 & 7504 & 7439 \\
$x_{2}^{\prime}(\mathrm{m})$ & 3865 & 3887 & 3789 & 3725 & 3830 \\
$-x_{3}^{\prime}(\mathrm{m})$ & 808 & 842 & 640 & 651 & 730 \\
$C\left(10^{3} \mathrm{~m}^{3}\right)$ & -53.36 & -43.91 & -23.42 & -23.60 & -11.28 \\
$C^{\prime}\left(10^{3} \mathrm{~m}^{3}\right)$ & -46.84 & -38.43 & -30.41 & -28.33 & -13.08 \\
$R M S E(\mathrm{~mm})$ & 3.07 & 3.89 & 2.30 & 1.47 & 2.36 \\
$R M S E^{\prime}(\mathrm{mm})$ & 3.15 & 4.21 & 2.38 & 1.58 & 3.33 \\
Figure & $2 \mathrm{a}, 2 \mathrm{e}$ & $2 \mathrm{~b}, 2 \mathrm{f}$ & $2 \mathrm{c}, 2 \mathrm{~g}$ & $2 \mathrm{~d}, 2 \mathrm{~h}$ & $2 \mathrm{j}$ \\
\hline
\end{tabular}

$C^{\prime}$ and $R M S E^{\prime}$ are calculated based on the constant source location at $x_{1}^{\prime}=$ $7445 \mathrm{~m}, x_{2}^{\prime}=3838 \mathrm{~m}, x_{3}^{\prime}=-735 \mathrm{~m}$. 


\section{Discussion and Conclusions}

[13] On the basis of the modeling results from five interferograms (Table 1), we conclude the summit area subsided more than $10 \mathrm{~cm}$ from 1995 and 2001. The depth of the deformation source is shallow (less than $1 \mathrm{~km}$ ), and the location of the best-fitting source is near but outside of the summit crater. The limited acquisitions of ERS data over Kiska plus loss of interferometric coherence during most of the year make it difficult to determine the temporal evolution of the subsidence very precisely. However, the subsidence rate was not constant between 1995 and 2001; rather, it peaked between 1999 and 2000. The subsidence rate during 1998-1999 was probably similar to 2000-2001, but both were larger than during 1995-1998 (see Table 1).

[14] We consider three possible mechanisms to account for the observed deformation. First, the deformation could be due to withdrawal of magma from a shallow chamber. However, this begs the question: where did the magma go? No eruptions occurred and flow out of a shallow reservoir into a much deeper one requires a loading mechanism to counter pressure gradients due to thermoelastic buoyancy [Turcotte and Schubert, 1982], for which there is no evidence. A second possible explanation is a poroelastic model in which subsidence is caused by a decrease of pore fluid pressure within a confined shallow reservoir. According to the model, heat flux into the reservoir increases pore fluid pressure until some critical pressure is achieved and the surrounding confining material is breached, producing the observed subsidence. A third possibility is a coupled system involving a deep magma chamber and shallow hydrothermal system. Magma chamber inflation causes a temporary increase in pore fluid pressure and subsequent diffusive decay within the hydrothermal system, which produces subsidence at the surface [Lundgren et al., 2001]. This mechanism would produce a relatively long-wavelength uplift signal prior to subsidence, which is not apparent in the InSAR images.

[15] We prefer the poroelastic model that is driven by thermoelastic expansion and repeated healing and failure of the confining material. For the estimated source strengths given in Table 1 and a lithostatic critical (maximum) pressure, the poroelastic model requires a value for $c_{m}$ to be greater than that for competent igneous rocks [Wang, 2000]. This suggests the shallow poroelastic reservoir is fractured, a condition consistent with the expected stress regime of an active volcano.

[16] Our proposed model is consistent with not only the large amounts of steam reported during recent eruptions of Kiska [Miller et al., 1998], but also field observations of persistent steam plumes in June-July 2001 [Jones et al., 2001]. Jones et al. [2001] also discovered a steam vent about $3 \mathrm{~m}$ in diameter located on the northwest flank just outside of the summit crater (I. Jones, pers. comm., 2002) (Figure 2). Hot steam vigorously shot out from the vent in June-July 2001 http://www.mun.ca/acwern/Kpix8a.html). The hori- zontal locations of our best-fitting sources are located within a few hundred meters of this vent (Figure 2). Ground-shaking that lasted up to several hours was also felt at a distance of about $3 \mathrm{~km}$ from the vent (I. Jones, pers. comm., 2002). We speculate that vigorous steam venting caused a decrease in pore-fluid pressure within the shallow hydrothermal system, which in turn was responsible for the observed subsidence.

[17] Acknowledgments. ERS-1/ERS-2 SAR images are copyright (C) 1995, 1998-2001 ESA, and provided by the NASA/ASF. This research was supported by funding from NASA (NRA-99-OES-10 RADARSAT-0025-0056 (Lu) and NRA-98-OES-13 SENH99-0123-0012 (Dzurisin)), and in part by USGS contract 1434-CR-97-CN-40274 and the USGS Land Remote Sensing and Volcano Hazards Programs. We gratefully thank I. Jones for sharing his field observations of Kiska volcano. We thank ASF staff for timely delivery of SAR data, W. Thatcher, T. Neal, B. Wylie and T. Albright for comments, and R. Rykhus for help on figures. Suggestions from two anonymous reviewers considerably improved the manuscript.

\section{References}

Delacourt, C., P. Briole, and J. Achache, Tropospheric corrections of SAR interferograms with strong topography: Application to Etna, Geophys. Res. Lett., 25, 2849-2852, 1998.

Dieterich, J. H., and R. W. Decker, Finite element modeling of surface deformation associated with volcanism, J. Geophys. Res., 80, 40944102, 1975.

Jones, I., C. Gray, J. Dusureault, and A. Sowls, Auklet demography and Norwar Rate Distribution and abundance at Sirius Point, Kiska Island, Aleutian Islands, Alaska in 2001, http://www.mun.ca/acwern/ finalKiskaREP.pdf, 2001.

Lu, Z., C. Wicks, J. Power, D. Dzurisin, W. Thatcher, and T. Masterlark, Interferometric synthetic aperture radar studies of Alaska volcanoes, Proceedings of IEEE 2002 International Geosciences and Remote Sensing Symposium, p. 191-194, Toronto, Canada, 2002.

Lundgren, P., et al., Modeling surface deformation observed with synthetic aperture radar interferometry at Campi Flegerei caldera, J. Geophys. Res., $106,19,355-19,366,2001$.

Massonnet, D., and K. Feigl, Radar interferometry and its application to changes in the Earth's surface, Rev. Geophys., 36, 441-500, 1998.

Miller, T. P., et al., Historically active volcanoes of AlaskaHistorically active volcanoes of Alaska, U.S. Geolo. Surv. Open File Rep., 98-582, 1998.

Mogi, K., Relations between the eruptions of various volcanoes and the deformations of the ground surface around them, Bull. Earthquake Res. Inst. Univ. Tokyo, 36, 99-134, 1958.

Press, W. H., S. A. Teukolsky, W. T. Vetterling, and B. P. Flannery, Numerical recipes in C, Cambridge University Press, 994 pp., 1992.

Turcotte, D. L., and G. Schubert, Geodynamics: Applications of continuum physics to geological problems, 450 pp., John Wiley \& Sons, New York, 1982.

Wang, H. F., Theory of linear poroelasticity: With applications to geomechanics, 287 pp., Princeton University Press, Princeton, 2000.

Williams, C. A., and G. Wadge, The effects of topography on magma chamber deformation models: Application to Mt. Etna and radar interferometry, Geophys. Res. Lett., 25, 1549-1552, 1998.

D. Dzurisin, USGS, David A. Johnston Cascades Volcano Observatory, 1300 SE Cardinal Court, Building 10, Suite 100, Vancouver, WA 986839589, USA. (dzurisin@usgs.gov)

Z. Lu and T. Masterlark, USGS, EROS Data Center, Raytheon ITSS, 47914 252nd Street, Sioux Falls, SD 57198, USA. (lu or masterlark@) usgs.gov)

J. Power, USGS, Alaska Volcano Observatory, 4200 University Drive, Anchorage, AK 99508, USA. (jpower@usgs.gov)

C. Wicks, USGS, 345 Middlefield Rd. MS 977, Menlo Park, CA 940253591, USA. (cwicks@usgs.gov) 